We must be careful not to throw out the baby with the bathwater. The normalisation principle is essentially a good one which has enhanced our perceptions of, and support offered to, disadvantaged individuals. There is a need to relate existing data on basic psychological processes to the phenomena which Dr Boucherat describes. Then, hopefully, we can start to bridge the gap between Wolfensberger's observation of, and ideals regarding, society, and Clifford's statement regarding the importance of the individual's internal world, his feelings, and his general state of mind.

\section{The Hospitals for Sick Children}

Great Ormond Street, London WCI

\section{REFERENCE}

${ }^{1}$ HebB, J. (1946) On the nature of fear. Psychological Review, 53, 259-275.

\section{Planning for bed needs}

DeAR SIRS

At some risk of being considered one of those doctors who hold entrenched positions, oppose necessary change and so on, I write in response to some of the points raised by 'Planning for Bed Needs and Resource Requirements in Acute Psychiatry' (S. R. Hirsch, Bulletin, December 1987, 11, 398-407). It was a laudable attempt to address a serious and difficult practical problem but I doubt if it is meaningful to quantify the value to a psychiatric service, on the basis of any statistical data at present available.

It may be naive to expect it, but there seems to be very little mention of quality in this debate. Some discussion of what constitutes 'quality' might indeed help to raise the standards of communication between ourselves, the general public, the 'media' and our political representatives.

Meanwhile I am puzzled by the Working Party's choice of 'activity' as the proposed sole criterion of the functioning of an active psychiatric service (since 'resource provision' and 'potential demand' are not characteristic of the service, but of the conditions within which it must operate). Obviously it is of some interest to any employer to know that an employee is active rather than idle; but it is useful activity, not activity per se, which an intelligent employer wants to maximise; that is, activity which contributes to the stated goals of the organisation.

From this point of view, what is required is, firstly, to define the goals of the acute psychiatric service in question; these may well vary from one community to another and indeed, probably ought to do so, since there are likely to be qualitative differences in the nature of the demand and how it is expected to develop in the foreseeable future. The next rational step would be an attempt to devise some way of estimating, quantitatively how far each unit of a given type of activity contributes to those goals. This would make it possible to estimate the 'useful activity output' of the service in question. To obtain a meaningful estimate of efficiency, this quantity should be divided by the total activity, which might be estimated broadly along the lines suggested by the Working Party (but more on that subject later).
This approach would be roughly analogous to the way in which efficiency is defined in other spheres, as 'useful work done' divided by heat or energy or work put in. It would not conflict with the queuing-theory approach so lucidly advanced by Dr Marjot (same issue of Bulletin). With respect, it makes little sense to define efficiency as 'work put in by the service' divided by 'money put into the service'. If an economic measure similar to productivity is what is required, then it should be defined as 'useful activity output' divided by 'money input'.

With these general principles in mind the suggested activity 'algorithm' (sic) seems to be at odds with any sort of community-orientated policy. The given formula implies that one patient admitted and discharged adds two points to the 'activity' score, whereas one domiciliary visit which prevents an inappropriate admission by mobilising other methods of support (such as CPN visits, which do not count!) adds only half a point. In other words-prevent an admission and you are penalised one and a half points. The weightings used in the formula seem to illustrate with exquisite aptness the point that useful activity-not aimless activity, not 'statistical' or fictional activity-is what a psychiatric service should be producing from its resources. Almost any formula will tell an interesting story - but some stories are more relevant than others.

I write in the earnest hope that the College will not allow itself to be drawn into supporting any further proposals for reorganisation, from no matter what ideological source, which do not rest on a basis of very well considered performance criteria.

Hugh B. G. Thomas

Middlewood Hospital, Sheffield S6 ITP

\section{Professor Hirsch replies}

\section{DeAr Sirs}

I agree with the overall direction of Dr Thomas' argument, and many of the points he makes, which are very important. It would be helpful if he and other readers interested in the subject would read the full report to get a better feel of the problem we are dealing with.

Ours is a report of what we are able to achieve with the limited amount of data painfully extracted pre-Körner while Dr Thomas' letter largely concerns itself with the direction in which the argument should continue to develop. Criticisms he makes apply equally well to the Körner data sets and the 'performance indicators' which the DHSS is currently developing. We were, in fact, completely unaware of the development of Körner until we finished our report, but they are both working on nearly the same lines.

It is the spirit of Dr Thomas' letter with which I have to disagree. It suffers from what I might call the 'reification fallacy'-a tendency to equate a measure of a thing to the whole of a thing, forgetting that it is only a measure. Our working party started out on the journey to try to identify how many beds, later redefined how great a resource, a district needs for its particular psychiatric service. We realised there was no absolute answer but that we could talk in comparative terms within the overall context of the Health 